\title{
Framing Supervisor Intentions and Actions for Hiring Candidates with a Disability
}

\author{
Mike Annett \\ MacEwan University
}

With considerable consequences, persons with a disability are less frequently hired than persons without a disability. In this study, semi-structured interviews elicit the beliefs and intentions that precede supervisor actions to select or bypass candidates with disabilities. Supervisor responses were mapped to the Reasoned Action Approach as an organizing and explanatory framework. The results show that supervisors had a wide array of antecedent beliefs and were generally positively intentioned toward hiring candidates with a disability. However, most supervisors did not actually select a candidate with disability and their rationalized non-hiring of such candidates to external factors rather than personal beliefs.

\section{INTRODUCTION}

Employment practices regarding persons with a disability and low rates of workplace inclusion are longstanding, widespread, and significant issues (Gewurtz, Langan \& Shand, 2016; Procknow \& Rocco, 2016). Kulkarni (2012a) reports that relative to non-disabled job candidates, candidates with a disability (CWD) encounter more hardships in securing and maintaining employment. In Canada and the United States, employment rates of persons with a disability are about a third lower than those without a disability (Statistics Canada, 2014, U.S. Department of Labour, 2016). The negative consequence of disabled person exclusion from workplaces are significant for the person. Having a job gives a sense of financial relief, but it also helps to improve social status, self-worth and societal inclusion. The opposite effects happen when one does not have a job to sustain a daily living; low self-value, lack of inclusion and withdrawal from society (International Labor Organization [ILO], 2015).

Negative consequences also materialize for employers. From an operational perspective, they may miss-out on a productive and long-term employee. Each of these attributes is generally accepted as desirable to employers. Additionally, they may miss-out on gaining access to a different worldview and other benefits of a more diverse workforce (Lengnick-Hall, Gaunt \& Kulkarni, 2008).

There are legal provisions to prohibit and permit discrimination on the basis of disability. Regarding prohibition, in Canada, federal and provincial Human Rights Acts restrict employment discrimination on the basis of disability. Similar legislation is present in most other countries (e.g., United States of America - Americans with Disabilities Act, Germany - General Equal Treatment Act, and Japan Elimination of Discrimination Against Persons with Disabilities Act) and the International Labor Organization maintains a Convention regarding the inclusion of PWD in society and in particular with regard to employment (2008). On the other hand, Bona Fide Occupational Requirements (BFOR), or 
similar provisions, enable legitimate employment selection discrimination on the basis of disability in certain circumstances.

In the privacy of interview rooms and internal decision spaces, selection decisions involve legal considerations but also supervisors' own ethical assessments and opinion of business operation factors (Durrani \& Rajagopal, 2016). It is reasonable to suggest the low employment rate of disabled person is also the result of supervisor concerns that CWD lack the traditional knowledge, skills and abilities for the job and are not fully or properly considered for the capabilities they do possess (Lengnick, Gaunt and Kulkarni, 2008; Jackson, 2000). Further that the low employment rate may be a result of negative supervisor attitudes towards the employment of disabled persons. For example, Annett (2017) and Carvalho-Frietas, et al (2015) show that some people articulate a clear low willingness to work with disabled persons. These concerns may be implicitly held as well as explicitly shared. As such, supervisors may intentionally discriminate against these candidates intentionally and influence others around them (Bodenhausen \& Macrae, 1998).

A primary function of this paper to suggest the Reasoned Action Approach (Fishbein \& Ajzen, 2010) as a suitable framework for mapping supervisor intention and actions regarding CWD, as well as accounting for moderating external factors. Corresponding illustrative examples of supervisors' own reflections on their intentions and actions help colour the framework.

\section{Disability and Employment in Human Resource Literature}

Procknow and Rocco (2016) conducted a comprehensive review of disability in the human resource literature published between 1999 and 2016. They state "[d]isability is an area that is sidestepped in the HRD literature" (p.381). My own review of disability in the literature shows a similar paucity of published academic writings in terms of human resource management systems and the employer-side of the selection process. Two of the most prominent writers are Mukta Kulkarni (e.g., Kulkarni, 2012a; 2012b; Kulkarni \& Kote, 2013, and Kulkarni \& Lengnick-Hall, 2014) and Dianna L. Stone (e.g., Stone, 1997; Stone \& Collela, 1996; Stone \& Stone, 2015; Stone, Stone \& Dipboye, 1992, and Stone-Romero, Stone \& Lukaszewski, 2006). These authors make plain the presence of negative attitudes and concerns of supervisors towards the employment of disabled persons.

Procknow and Rocco (2016) identified the following categories of desirable inquiry: a) Organizational Entry Barriers, b) Organizational Post-entry Barriers, c) Career Development and Advancement, d) Workplace Training for Disability Inclusiveness, e) Workplace Training for Disabled Employees, and f) Harassment and Discrimination. Of these categories, Organizational Entry Barriers is taken-up in this study. Within that category they highlight pressing opportunities for addressing employer-side barriers as: a) attitudinal barriers (e.g. prejudices, biases, and stereotypes), and b) institutional barriers (e.g. standard assessment processes, and company policies).

To the best of my knowledge, presentations of theory-driven explanations of the negative attitudes of supervisors and the role of their concerns in selection decisions are absent from the human resource management disability literature. To address this gap, and working in the exploring phase of literature development (von Kraugh, Ross-Lamastra \& Haelfiger, 2012), I suggest the Reasoned Action Approach (Fishbein \& Ajzen, 2010) as an underlying conceptual framework for mapping supervisor intentions and actions for CWD employment. I further introduce and relate findings from interview data with supervisors to illustrate that framework. These contributions help answer why workplace exclusion for persons with a disability continues to be a challenge, and what can be done about it.

\section{Reasoned Action Approach and Supervisor Intentions and Actions}

The 'knowing-doing gap' is one way to paraphrase the long-standing recognition that there is a difference between intending to do an act, and actually performing that act. The Reasoned Action Approach (Fishbein \& Ajzen, 2010) presents a solid, but not exhaustive, articulated framework for the interconnection of Intention, Behaviour, and the moderating effect of Actual Control. This framework is presented in Figure 1. 
FIGURE 1

SIMPLIFIED REASONED ACTION APPROACH FRAMEWORK

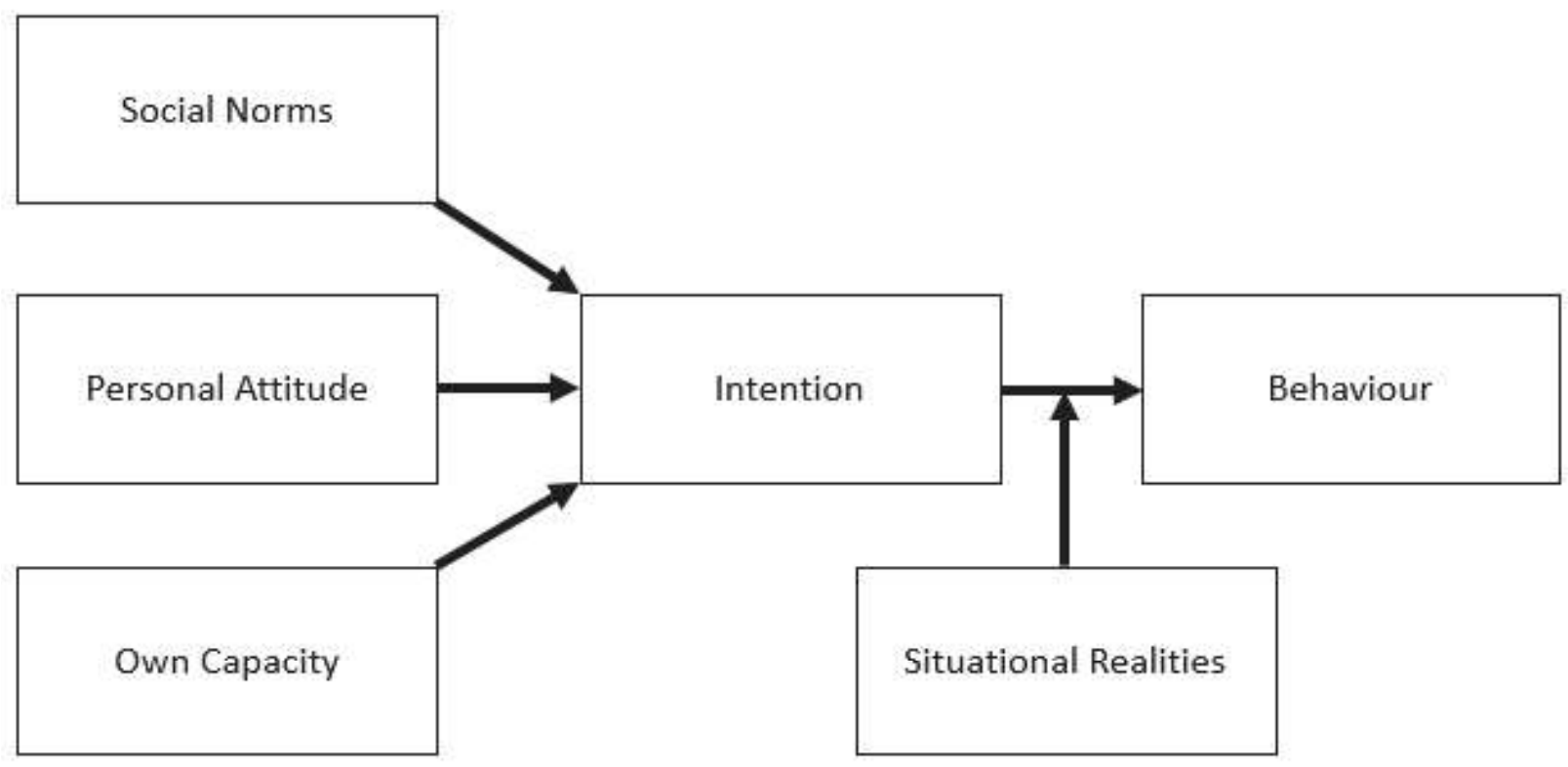

Adapted from Fishbein \& Ajzen (2010).

The Reasoned Action Approach (RAA) is a well-established explanatory framework and wellreferenced in behavioral science studies (Ajzen, 2012). Pertaining to supervisor intentions and behaviors towards CWD, the primary antecedent concepts generally apply as follows:

- Behavior: The act of a supervisor making an employment offer to a CWD. This may also involve the act of fully assessing the qualifications and abilities of the CWD as part of the selection process as a precursor behavior to making the employment offer.

- Intention: The supervisor's interest and proclivity to making an employment offer to a CWD.

- Social Norms: The supervisor's awareness of social acceptability and/or pressure for making an employment offer to a CWD. This includes what the supervisor feels they ought to do, and what others are doing (or not doing).

- Personal Attitude: A general predisposition to making the employment offer to a CWD. This includes anticipated and experienced positive and negative consequences.

- Own Capacity: The supervisor's belief that they can make the employment offer to a CWD. That is, they have the ability and authority to make the offer.

It is also pertinent to identify a generalized moderating variable that may interrupt or accentuate intentions becoming actions:

- Situational Realities: Factors internal and external to the supervisor that interrupt or accentuate their intentions becoming actions. This includes their actual capacity and authority for making an employment offer to a CWD, as well as corporate leadership and directives, human resource policies and processes, and business operating conditions.

With the above RAA concepts identified and annotated with disability perspectives, the underlying mechanisms of supervisor intentions to make an employment offer to a CWD become more clear. 


\section{METHOD}

This was an exploratory study to surface and organize the intentions and actions of supervisors for making offers of employment to CWD. This study appears to be the first qualitative study drawing directly supervisors in this regard and relatable findings are not yet present in the literature.

Data were collected through semi-structured interviews. Following a grounded theory approach (Strauss \& Juliett, 1994) I solicited supervisor comments and explanations of the factors they perceived instrumental to the intentions and behaviours for employing disabled persons. This included personal beliefs and experiences, social pressures, and business obligations.

I interviewed 20 supervisors from small and medium-sized enterprises in a large city in Western Canada. Following the guidance of Bachiochi \& Weiner (2002), a semi-structured interview research method was chosen for this study for the following reasons: First, this research is exploratory. The objective was to discover how and why supervisors perceive hiring CWD and whether their behaviors align with their intentions. Second, open-ended questions allow participants the opportunity to explain their feelings more fully. Participants were able to share experiences and provide interpretations that were not anticipated. Third, an interview method provided an opportunity to obtain greater depth and richness of data than what is typically gained from questionnaire surveys.

Previous experience interviewing supervisors led me to believe that participants would only speak candidly about their perceptions and actions when there was a mutual perception of trust and nonjudgement. Conditions of anonymity were strictly maintained, and in most cases two or three relationship building conversations took place prior to the formal research interview. Interviews took place in supervisors' offices with no other people present. Each supervisor was provided an advance copy of the interview themes and questions, were asked the same set of questions, and encouraged to respond in an open-ended fashion.

The interviews occurred over a period of several months in late 2016 and early 2017 . The question protocol was based upon an extensive review of the literature on the employment of disabled persons. Questions covered the following issues: a) organizational profile including characteristics (e.g., industry, size) and actions (e.g., competitiveness, corporate social responsibility, innovation), b) supervisor involvement in selection processes, c) personal and organizational influences on selection decisions, and d) experiences hiring CWD.

Interviews ranged in length from 25 minutes to 60 minutes. All interviews were audio-recorded and transcribed for analysis. During the process of coding and organizing this information it became evident that supervisor reflections aligned closely with the Reasoned Action Approach. Subsequently, I mapped the interview data to the RAA as an organizing framework.

\section{ANALYSIS AND RESULTS}

In the following section I outline supervisor responses describing actual employment offer extensions or denials to CWD, their general intentions for making such offers, and reflections on the three antecedents to Intention (Social Norms, Personal Attitude, and Own Capacity). I also indicate the Situational Realities that inhibited or facilitated supervisor Intentions to Behaviors. The responses are aggregated to provide an overall picture of the nature of reasoned action in extending an offer of employment to CWD, rather than independent paths. This is due in part because the descriptive information for each respondent is not complete and the general picture is more apparent in the aggregate.

\section{Behaviors}

The group of supervisors had extended five offers of employment to CWD and chose not to extend offers to two CWD. This means that thirteen supervisors were not in an active position for translating intentions to behaviors. The supervisors talked about their behaviors in several different fashions.

First, those that actually made a hire described them as having an intent of permanency. Although there is a recognition that the employment relationship could end at some point, there was no planned 
sunset on the CWD employment. For example, when Supervisor 02 was asked about the duration of the commitment, he said:

It's just going to be ongoing. You know, providing that nothing changes within our operation and nothing happens to him ... You can tell he still enjoys coming here. He gets excited. If something changes and suddenly he seems, you know, disengaged when he's here or, you know, dissatisfied with coming in, then maybe we'll review...

Second, they described their hiring action as relatively normal. For example, Supervisor 11 described the type of work as being tasks normally performed by his other employees:

Just simple things like cleaning with the mop or anything like sweeping and like in that bigger shop you need somebody sweeping a couple of hours a day. So he worked three or four hours a day, every day. It worked out well for us.

Other managers shared a similar sentiment:

Someone that would come and maybe mow the lawn or clean floors or something... that needs to get done but we wouldn't hire someone necessarily to do that full-time. (Supervisor 12)

We were able to craft some responsibilities and projects for people to help us out with.... A lot of files and forms. It freed up a lot of time for our full-time staff to get stuff that they needed done. (Supervisor 09)

They're kind of tasks that somebody has to just fit in ... Freeing up some other people to do core duties that they have. (Supervisor 04)

The declinations to extend and offer of employment both related to CWD assessed task performance. For example:

The gentleman was in his 80 s and had challenges moving around. He had a handicap (decal) in his car. That person was a seasoned veteran in sales. So he's already learnt all those things, but the problem is that I don't think he can get around inside customer houses very well. (Supervisor 8 )

I didn't think my vacant position was a good fit for the person. It was going to require a quite a bit of accommodation to make it work and I don't have the resources to do it. (Supervisor 15)

Broadly speaking, the supervisors were accountable to their decision to hire or not hire a CWD. They had reasons that they considered legitimate and all appeared comfortable explaining themselves and their actions.

\section{Intentions}

Supervisors were clear about having an intention to extend or withhold an offer of employment to a CWD. Most supervisors held positive intentions, although some were strong and others were weak. The following examples illustrate different attributes of such intentions:

I think it is right thing to do to give everybody a chance. Especially, people with disabilities. They have it so hard already. (Supervisor 11) 
We haven't hired a disabled person yet but are working with an employment agency right now to make that happen. I know it can be intimidating to deal with somebody with a disability, everybody would just almost grow up a little bit and not be so afraid of interacting with other humans. (Supervisor 3)

Yah, sure, why not? As long as they can do the job it doesn't matter to me what background or issues a person has. (Supervisor 4)

It's all about how much money you make for me. You know, maybe he's a little slow, give him a try but it comes down to the fact that if it takes him a day to make (product) I'm not making money. Now, if he can make (product) faster than anybody, he'll be making more money than anybody. (Supervisor 1)

I would have to look at supports and services the person needed. If it is not too much I would be open to the idea. (Supervisor 12)

Some supervisors also expressed disinterest with making an offer of employment to a CWD. For example:

I don't know any disabled persons to make an offer to. I haven't had any apply, either. (Supervisor 17)

I'm a bit embarrassed to say this, but I don't really want to. It seems like a lot of extra work. (Supervisor 20)

No, not really. (Supervisor 8)

In aggregate, 13 positive statements and four neutral and three negative statements were made regarding personal intention about making an offer to a candidate with disabilities. Based on the responses supervisors perceived hiring a CWD as a possible event, but some expressed it as much more probable than others.

\section{Social Norm}

Several supervisors clearly felt social influence for and against employing a disabled person. However, most were neutral or indifferent to what others were saying or doing.

Regarding positive social influence, the following quotes illustrate the situation:

I am part of a business network that promotes the employment of persons with disabilities. They would look at me sideways and have hard questions if they thought I wasn't interested in hiring a disabled person. (Supervisor 1)

A few branches in the company have made affirmative action hires for disability. I see how it is working out for them, and the kudos they are getting. If the opportunity comes up for me I can now see that it's a celebrated thing. (Supervisor 3)

Regarding the negative social influence, the following quote illustrates the situation:

I think people would be upset with me. They would wonder why I am not thinking about the best interests of the team and company's performance. (Supervisor 13) 
In aggregate, five positive statements and three negative statements were made regarding social norms influencing their intentions. The remaining 12 supervisors provided either neutral responses, or not cogently addressed. Based on the responses supervisors perceived social norms as a plausible but most non-significant factor for their intentions to extend an offer to a CWD.

\section{Personal Attitude}

Supervisors' individual disposition towards persons with disabilities was mostly expressed as indifference, with nearly all claiming that they have little direct, working exposure to persons with disabilities. Two examples of supervisor's that did express a clear opinion are:

I'm an inclusive kind of person ... so it's always been my nature, just to always make sure everyone feels like they're included like everybody else. (Supervisor 04)

And frankly I think a big part of it has been my wife who's always volunteered and been very active with supporting those with disabilities or injury, or some sort of loss. So having been with her now for several years its rubbing off on me and I think before I was just a lot more selfish and self-centered. (Supervisor 18)

As such, most supervisors indicate they do not feel positive or negative about the potential employment of a CWD, except to be worried about practical matters of safety and job performance. The following quotes illustrate those concerns:

It would just be too difficult for that person ... sometimes dealing with the public is not fun for individuals like that because sometimes you get really nasty individuals (Supervisor 6)

So that would be the biggest challenge - how much of this job is actually safe and suitable and if a good portion of it is actually the production tasks. In that case, then, you'd rather have somebody who's safe (not disabled) and the safe people who are doing the production tasks also pick up some of the organizing and cleaning rather than putting somebody in a difficult situation or unsafe situation. (Supervisor 20)

You don't know what you're getting into. I had last week somebody ask me for a job and they have Asperger's. I was like, I don't know, what can he do, what can't he do? (Supervisor 5)

Additionally, some supervisors had a more difficult time seeing the 'win' for them in hiring a CWD, which negatively affected their intentions. For example:

I could put time into researching the disability, but most people don't want to put that time into it. I don't want to put the time into it. (Supervisor 19)

I really don't see how this is going to work in the long-term. It seems like a bit of a charity effort on my part. (Supervisor 17)

In aggregate, three positive statements and three negative statements were made regarding personal attitudes towards CWD. The remaining 14 supervisors provided either neutral responses or non-cogent answers. Based on the responses supervisors perceive their own attitudes as having minor impact on their intention to extend an offer to a CWD. 


\section{Own Ability}

Most supervisors felt positive that they could make an offer of employment if they wanted to. Said differently, a few supervisors felt they would have to persuade another person to endorse the offer of employment. Otherwise, they held the power to make the offer. For example:

I would want to check with my fellow supervisors just to see what their thoughts are on that. Would they think it might not be a good idea, or a good idea? And then, ultimately the decision would be with me, but I definitely would check with everybody that it's going to affect and make sure of that. (Supervisor 14)

A few supervisors expressed some generalized uncertainty about their own capacity to supervise a CWD. For example:

It's always a great idea to hire CWD, but truthfully, I am a little unsure about how to go about doing it. (Supervisor 3)

We were unsure about the training of them and how to handle if a mistake is made, or if they're unsure of what's happening. (Supervisor 16)

In aggregate, 17 positive statements and three negative statements were made regarding supervisors' own capacity to extend an offer of employment to a CWD. Based on the responses supervisors recognize the importance of having personal authority in the hiring process to their intention to extend an offer to a CWD.

\section{Situational Realities}

Although a majority of supervisors have general positive intentions towards hiring a CWD only seven were in the active position to actually extend or deny an offer of employment. For those in the active offer situation, some situational realities that affected their behaviors were the presence and enforcement of diversity programs, leadership directions, and the constraints of the business operation and economy. For example:

I wasn't going to hire the girl. But, my human resources officer reminded me about diversity and inclusion program and asked if I could find a way to make it work. (Supervisor 9)

The foreman, had a cousin ... looking for a job and he wanted something and he had a disability. And it was like, well yes I'll give him a shot because I didn't know anything about it at that time, so it's like 'well the foreman's asking' so we should give it a shot to try it out. (Supervisor 2)

He was going to be on a disability subsidy as well, so they paid some of it ... to me it was a very good deal. Why wouldn’t you do it, right? Why hire some guy for $\$ 20$ per hour when this other person is available for $\$ 15$ ? (Supervisor 11)

We had just laid-off of a few people. I couldn't very well make a job offer to a person that needs accommodations when we couldn't keep able-bodied people last month. It wouldn't play well. (Supervisor 08)

Supervisors that were not in the position to actually decide to extend an offer to a CWD still had perspectives on what might influence them to extend an offer or not. For example: 
I have heard about cash mob and other business-helpful marketing things that happen when you hire a disabled person. That's not my primary reason for hiring a disabled person but it would help. (Supervisor 3)

But, there are probably somethings I would not feel comfortable giving to him just because I don't know if its going to get properly done. In our business I don't think I'd have time to slowdown and fix mistakes (Supervisor 06)

To summarize this portion, it became evident that situational realities were strong forces on the actual behavior of extending an offer of employment. Specifically, these realities helped supervisors legitimize their decisions to extend or deny an offer of employment to a CWD.

\section{DISCUSSION}

The RAA framework clearly helps organize supervisor reflections about their intentions and behaviors for making offers of employment to CWD. Of the antecedent factors for Intention, it seems that the Own Capacity was the most closely connected to positive intentions to hire a CWD. Negative intentions were most closely related to Personal Attitude and the absence of Social Norms.

Of the connection between Intention and Behavior, it appears that positive or negative intention is likely to carry through to offer or denial of employment. That is, except for one explicit occurrence in the 'actual case', a positive intention does not become negative action, or vice versa. However, in the 'hypothetical' situation, it was more likely that supervisors would find Situational Realities that inhibit the offer than enable the offer.

\section{Limitations}

The study is presented as an exploratory work seeking to organize and map supervisor reflections towards CWD. As such, there are several limitations that constrain the study. First, the data is singleauthor coded and making it open to subjective interpretation and bias. Second, the data is drawn from a local, convenience sample of organizations without controls for industry and organizational size. These may inhibit broader generalizability. Third, the reflections were mapped to an existing explanatory framework, rather than constructed through the natural thrust of the supervisor explanations. As such, it is possible that additional variables outside of the those addressed by the RAA are influencing Intentions and Behaviors.

While the above limitations do present issues for the study they do not negate the quotations themselves. As such, study presents useful insight to the thinking of supervisors regarding employment of CWD.

\section{Further Work}

The RAA is shown to be a suitable framework for mapping supervisor intentions. Additional efforts to map qualitative expressions to the framework will help to solidify the categorical utility of the framework.

Empirical research is also beneficial to better articulate the presence and respective strength of connections between the antecedent factors (Social Norms, Personal Attitude, and Own Capacity) to Intentions, as well as the moderating power of various Situational Realities for the connection between Intention and Behavior. 


\section{CONCLUSION}

This paper began by indicating that persons with a disability are too frequently excluded from employment. While this is well known, the factors and psychological processes involved in supervisors taking actual steps to the employment of CWD and resolving this disparity are less clear. This study served to unpack some of these factors and processes. Mapping supervisor responses to the Reasoned Action Approach provided structure and clarity and revealed that supervisor intentions to hire a CWD are informed by a wide array of antecedent perceptions and situational realities.

Further work in this area is required to extend the generalizability of supervisors comments, more fully map and affirm the application of the reasoned action approach to PWD staffing behaviors, and identify mechanisms of best influence for hiring managers to cross the 'intending-doing' gap in CWD employment.

\section{REFERENCES}

Annett, M. (2017). Categorizing supervisor reflections on risks of hiring persons with disabilities. Journal of Organizational Psychology, 17(4), 29-35.

Ajzen, I. (2012). Martin Fishbein's legacy: The reasoned action approach. The Annals of the American Academy of Political and Social Science, 640, 11-27.

Bachiochi, P.D., \& Weiner, S.P. (2002). Qualitative data collection and analysis. In S.G. Rogelberg (Ed.), Handbook of research methods in industrial and organizational psychology (161-183). London: Blackwell.

Bodenhausen, G. V., \& Macrae, C. N. (1998). Stereotype activation and inhibition. Advances in Social Cognition, 11, 1-52.

Carvalho-Freitas, M.N., Souto, J.F., Simas, A.L., Costa, N.B., Santos, L.M.M. \& Marques, A.L. (2015). Willingness to work with persons with disabilities in future Brazilian professionals. Work, 50 , 543-552.

Durrani, A.S., \& Rajagopal, L. (2016). Restaurant human resource managers' attitudes towards workplace diversity, perceptions and definition of ethical hiring. International Journal of Hospitality Management, 53, 145-151.

Fishbein, M., \& Ajzen, I. (2010). Predicting and changing behavior: The reasoned action approach. New York: Psychology Press.

Gewurtz, R., Langan, S. \& Shand, D. (2016). Hiring people with disabilities: A scoping review. Work, 54(1), 135-148.

International Labor Organization [ILO]. (2008). ILO vocational rehabilitation and employment (disabled persons) convention (No. 159) and recommendation (No. 168). Geneva: ILO

International Labor Organization [ILO]. (2015). ILO and disability inclusion. Geneva: ILO.

Jackson, C.J. (2000). Employer willingness to comply with the disability discrimination act regarding staff selection in the U.K. Journal of Occupational and Organizational Psychology, 73 (1), 119129.

Kulkarni, M. (2012a). Contextual factors and help seeking behaviors of people with disabilities. Human Resource Development Review, 11, 77-96.

Kulkarni, M. (2012b). Social networks and career advancement of people with disabilities. Human Resource Development Review, 11, 138-155.

Kulkarni, M., \& Kote, J. (2013). Increasing employment of people with disabilities: The role and views of disability training and placement agencies. Employee Responsibilities and Rights Journal, 26(3), 177-193.

Kulkarni, M., \& Lengnick-Hall, M.L. (2014). Obstacles to success in the workplace for people with disabilities: A review and research agenda. Human Resource Development Review, 13, 158-180.

Lengnick-Hall, M.L., Gaunt, P.M., \& Kulkarni, M. (2008). Overlooked and underutilized: People with disabilities are an untapped resource. Human Resource Management, 47(2), 255-273. 
Procknow, G., \& Rocco, T.S. (2016). The unheard, unseen, and often forgotten: An examination of disability in the human resource development literature. Human Resource Development Review, 15(4), 376-403.

Statistics Canada. (2014). Insights on Canadian society: Persons with disabilities and employment. Catalogue no. 75-006-X.

Stone, D.L. (1997). Overview: The impact of the ADA on human resource management. Human Resource Management Review. 7(1), 1-4.

Stone, D.L., \& Colella, A. (1996). A model of factors affecting the treatment of disabled individuals in organizations. Academy of Management Review, 21, 96-104.

Stone, C., \& Stone, D.L. (2015). Factors affecting hiring decisions about veterans. Human Resource Management Review. 25(1), 68-79.

Stone D.L., Stone, E.F., \& Dipboye, R.L. (1992). Stigmas in organizations: Race, handicaps, and physical unattractiveness. In K. Kelley (Ed.) Issues, theory, and research in industrial and organizational psychology, (384-444). Amsterdam: Elsevier.

Stone-Romero, E.F., Stone, D.L., \& Lukaszewski, K. (2006). The influence of disability on role-taking in organizations. In A.M Konrad, P. Prasad, and J.K. Pringle (Eds.) Handbook of Workplace Diversity, (401-430). Thousand Oaks: Sage.

Strauss, A., \& Juliet, C. (1994). Grounded theory methodology: An overview. In N. Denzin \& Y.Lincoln (Eds.) Handbook of qualitative research, (273-284). Thousand Oaks: Sage.

U.S. Department of Labor. (2016). Persons with a disability: Labor force characteristics-2015. Economic News Release. Retrieved from https://www.bls.gov/news.release/disabl.nr0.htm

von Krogh, G., Rossi-Lamastra, C., \& Haefliger, S. (2012). Phenomenon-based research in management and organization science: When is it rigorous and does it matter? Long Range Planning, 45(4), 277-298. 